\title{
Los usos del pragmatismo o cómo hacer sociología con filosofía
}

\author{
Philippe Schaffhauser ${ }^{1}$
}

Fecha de recepción: 17 de junio de 2013

Fecha de aprobación: 7 de octubre de 2013

\begin{abstract}
Resumen:
El pragmatismo y la sociología son, por decirlo así, primos hermanos ya que fueron engendrados en la segunda mitad del siglo XIX por la modernidad y la imperiosa necesidad de contrastar procesos sociales y económicos mediante una postura científica, crítica y participativa. Sin embargo este lazo de parentesco no significa que en la actualidad se haya dado una relación real a través de la constitución por ejemplo de un programa sociológico de corte pragmatista. La tradición pragmatista no es sino una fuente entre muchas otras para el pensamiento de autores tan diversos como son Jürgen Habermas y David Bloor. Lo único que encontramos cuando se revisan las fuentes son contados casos de acercamiento teórico entre ambas miradas y formas de acción, esto es, mediante textos de Emilio Durkheim (1913-1914), Charles W. Mills (1968) y hoy día con Hans Joas (1998 y 2002). En este artículo se pretende discutir sobre los posibles aportes del pensamiento pragmatista para la reflexión sociológica, los cuales giran en torno a buscar soluciones a problemas metodológicos-teóricos. En este sentido la concepción "práctica" de la realidad social como un proceso continuo y situado en un espacio "plástico" o, conforme a G.H. Mead y John Dewey, el re-planteamiento del concepto de acción social como "acción creadora culturalmente situada" pueden ser de gran interés para ampliar las perspectivas de la reflexión sociológica.
\end{abstract}

Palabras clave: Sociología, Pragmatismo, Acción Creadora, Creencia y Continuidades.

\begin{abstract}
Pragmatism and sociology are sort of first-cousins as both emerged from modernity in the second half of the nineteenth century, upon the need to contrast social processes with economic ones from a scientific, critical and participative approach. However, this does not mean there is currently a
\end{abstract}

1 Dr. en sociología, Profesor-Investigador titular "C", Centro de Estudios Rurales, El Colegio de Michoacán, Martínez de Navarrete 505 Fracc. Las Fuentes, Zamora. CP 59699, Michoacán. Tel y fax: (351) 515 7100. cer@colmich.edu.mx, schaffhauser@ colmich.edu.mx 
real link between the two of them given by, for instance, the development of a sociological programme based on pragmatism. The pragmatic tradition is only one of the many other sources for various thinkers like Jürgen Habermas and David Bloor. The only theoretical link and ways of action connecting these two disciplines are given in cases such as Emilio Durkheim (1913-1914), Charles W. Mills (1968) and nowadays Hans Joas (1998 and 2002). This article aims at discussing about the potential contributions of the pragmatic thought to the sociological one in order to find answers to methodological and theoretical problems. In this sense, the "practical" conception of the social reality as a continuous process placed in a "plastic" space, as stated by G.H Mead and John Dewey, reshaping the social action concept as a "creative action culturally placed" may be of help to expand sociological perspectives.

Key words: sociology; pragmatism; creative action; belief and continuities

"Au commencement était l'action."

(Goethe in Faust I citado por Boutroux, 1911: 50)

\section{Introducción}

La palabra pragmatismo es una voz polisémica (Schaffhauser, 2004). Existen varias interpretaciones al respecto que reflejan la compenetración entre varios campos como son las ciencias políticas, el discurso mediático-informacional, la política en tanto quehacer público, las ciencias económicas, las ciencias sociológica y antropológica y, last but not least, el sentido común. Ante esta posible confusión, la respuesta bien podría ser pragmatista y remitir, además, a una famosa advertencia del segundo Wittgenstein: "No buscar el significado de una palabra sino el uso, porque su uso es su significado". Por su lado William James consideraba que la palabra "pragmatismo" era un término nuevo para significar viejos problemas (James, 1945).

Por ende el pragmatismo, muy a menudo, sigue siendo considerado por gran parte de la comunidad sociológica como una filosofía de segunda clase, ya que, como decía Bertrand Russell (Putnam, 1999: 19), no es sino un pensamiento norteamericano 
puesto al servicio de la codicia del empresario capitalista común y cualquiera. En este sentido el pragmatismo parece primo hermano del utilitarismo vulgarizado de Benjamín Bentham por autores como John Stuart Mill y Henry Sidgwik. Para sus críticos, el pragmatismo se ha vuelto hoy día la filosofía del hombre político neoliberal que privilegia el realismo económico sobre cualquier otra posición política, considerando que otro posible enfoque no es válido por el hecho de permanecer alejado del contacto con la realidad, cuando de lo que realmente se trata es de una relación con una ideología de corte económico y neoliberal (como visión, división y versión del mundo) que al igual que cualquier otra ideología, ha vuelto la realidad natural, es decir única, monolítica e incuestionable. El mandamiento "hay que ser pragmático..." significa ser realista, práctico y se convierte en una postura que posibilitaría objetividad e imparcialidad, pasando por alto, claro está, sus fundamentos axiológicos relacionados con la economía política que se plantea a sí misma como una ciencia natural caída del cielo y puesta al servicio de la razón humana (que no una disciplina histórica surgida en un momento preciso del acontecer social y político de ciertas sociedades occidentales).

En otras ocasiones el pragmatismo ha sido reducido a no ser sino una filosofía del sentido común, del sentido práctico con base en el cual actúan los sujetos sociales y culturales, esto es, una suerte de conocimiento empírico poco compatible con la resolución de grandes problemas teóricos que pretende atender la tradición racionalista, inclusive con su derivación en las opciones del paradigma positivista que fundamenta la razón a través de la observación y cotejo de realidades empíricas. El pragmatismo ha sido tachado de ser una filosofía desesperanzadoramente senci1la. Ambas lecturas reflejan un sesgo evidente donde se compenetran argumentos intelectuales y explicaciones etnocéntricas, ya que el pragmatismo no es sino una expresión histórica de la cultura anglosajona y, claro está, norteamericana. Para sus partidarios tanto como para sus adversarios, el pragmatismo sería, bajo este enfoque, la ciencia del realismo, la "filosofía de la verdad" 
como resultado de una voluntad dispuesta a todo con tal de conseguir lo planeado, esto es, la persecución de un fin determinado que justifica el uso de medios cualesquiera, morales o no tales. Esta lectura tiene que ver con la comprensión de la teoría de la verdad de William James que tantas críticas ha recibido: uno por ser un producto del pensamiento empresarial norteamericano y segundo por dar la espalda a la tradición racionalista obsesionada por la búsqueda de los orígenes, esto es, lo que llamaría yo la filosofía de las esencias.

El pragmatismo es una fuente con la cual parece interesante entablar un diálogo tal como lo ha construido el sociólogo alemán Hans Joas, a través de sus múltiples trabajos sobre la relación entre el pragmatismo de G.H. Mead (2007) y el movimiento pragmatista por un lado y la filosofía y la sociología continentales, especialmente las alemanas por otro. Mi objetivo en este artículo es, entonces, construir las condiciones de un diálogo entre la Tradición Sociológica, con todo y su abanico de objetos de estudio y corrientes teórico-metodológicas para atenderlos, y el movimiento pragmatista, con todo y su diversidad. Sin embargo dado el espacio no muy amplio del que dispongo para realizar este ambicioso programa, me limitaré por ahora sólo a presentar algunas tesis del pragmatismo para reflexionar luego sobre cómo éstas se compaginan con el pensamiento y quehacer sociológicos, dando cierta prioridad a la sociología cualitativa norteamericana, la cual ha estado por obvias razones más directamente en contacto con esta influencia filosófica.

\section{Elementos para entender el pragmatismo y sus puntos de contacto con la sociología}

Con el paso del tiempo, el pragmatismo ha corrido la suerte de toda nueva propuesta filosófica o científica en el momento de su recepción por la academia -recordemos en esta tesitura la reacción negativa de la sociología francesa para con la escuela de 
Chicago, la ecología urbana con tinte pragmatista, en tiempos del apogeo del paradigma marxista o bien el desconcierto que provocó el segundo momento filosófico de Ludwig Wittgenstein, el de los juegos de lenguaje, empezando por la feroz crítica de su ex mentor, Bertrand Russell-, es decir, en tanto nuevo abordaje del pensamiento y de la acción propició críticas, recelos y comentarios que finalmente tergiversaron su contenido. Sin embargo no creo que, cuando hablamos de pragmatista hoy día y de sus influencias en la reflexión en las ciencias sociales, estemos presenciando una suerte de "revolución científica", es decir, en palabras de Thomas S. Kuhn, un cambio de paradigma que implica el desplazamiento paulatino de otro anterior que dictaba los programas de investigación y la construcción teórica (Kuhn, 1971), esto es, la visión que sobre el mundo tiene la ciencia dominante. Esto es por dos razones principales que muy escuetamente voy a resumir: 1) lo que analiza Kuhn en su famoso libro concierne sobre todo a las llamadas ciencias naturales y exactas (las ciencias de la cultura como las designaba Max Weber obedecerían a otro tipo de examen epistemológico pericial), y 2) que, lo que constituye la principal razón, el pragmatismo no es un paradigma como lo son el funcionalismo, el estructuralismo o el marxismo y sus variantes y combinaciones posibles, sino que es una metodología. En palabras de Kuhn, el pragmatismo nunca será una "ciencia normal", porque sería para este pensamiento incurrir en una contradicción. Por tanto el pragmatismo no es en sí una teoría del conocimiento, sino una reflexión metodológica sobre la producción del conocimiento, esto es, una epistemología. El pragmatismo es un método y no una escuela filosófica propiamente dicha. Su tarea consiste en destrabar problemas y cazar problemáticas fantasmas, como es la filosofía de la duda de corte cartesiano que se prolonga en la fenomenología de Husserl, a través del método del epochè. Es un método para aclarar las ideas considerando que la acción, esto es la investigación, es la vía y principal herramienta para ello (Peirce, 1877 y 1878). 
El pragmatismo se caracteriza por su antidualismo y antiesencialismo. Cuando hablo de Pragmatismo (con "P" mayúscula) me refiero explícitamente al movimiento filosófico impulsado en Estados Unidos por el lógico y matemático Charles S. Peirce (1839-1914) y al cual adhirieron primero William James (1842-1910) y posteriormente John Dewey (1859-1952), movimiento hacia el cual se identificaba con calado George H. Mead (1863-1932), amigo y colega del anterior en la Universidad de Chicago, a principios del siglo XX. En este sentido y a manera de presentación escueta, el pensamiento pragmatista se caracteriza por ser: 1) una filosofía de la acción como metodología para destrabar enredos filosóficos (Peirce, 1984); por considerar que, en palabras de James, 2) la realidad es práctica (Lapoujade, 1997: 82 y Dewey, 2000: 72), es decir que es procesal, parcialmente indefinida e infinita y lo que justamente posibilita la acción; 3) el papel de la investigación como forma de acción para dilucidar problemas (Peirce, 1978 y Dewey, 1993), 4) el papel de la creencia (que no sólo es de índole religiosa sino social y cultural) como guía de la acción (Peirce, 1984: 144-150 y James, 1999); 5) la identidad profundamente social de la personalidad, lo cual ha dado pie a la ciencia psicológica social fundada por Mead; 6) el rol del conocimiento cuyo significado sólo tiene sentido toda vez que se despliega en el curso de una acción (Dewey); 7) una ética de la responsabilidad como proceso (Dewey citado por Geertz, 1999:39); 8) por haber propiciado un giro lingüístico cuya consecuencia central ha sido el "des-psicologizar" el problema de la mente para considerarlo como un asunto netamente gramatical (Wittgenstein, 1988 y Ryle, 2005), y finalmente, 9) el pragmatismo se caracteriza por asumir una posición filosófica aparentemente contradictoria que es la conjunción del escepticismo con el falibilismo (Putnam, 1999: 36) pues no podemos, dicen los pragmatistas -y contrario a lo que creían Descartes o Husserl-, dudar de todo, ya que la duda verdadera (es decir relacionada con la realidad) estriba en algo que está fuera de toda disquisición (esto tiene que ver con la imposibilidad de tematizar el 
conjunto de elementos que conforman el universo de creencias) y que fungen en tanto que creencias básicas, y el falibilismo, esto es, nuestro conocimiento vuelto creencia sólida tiene fecha de caducidad, algún día dejará de guiar nuestra acción.

En el plano más estrictamente sociológico, la influencia del pragmatismo ha surtido efecto para orientar ciertos abordajes característicos de la experiencia micro-sociológica, a través de un pionero de los momentos de la escuela de Chicago como William Isaac Thomas (1863-1947) y posteriormente de los estudios y ensayos de Erving Goffman (1963 y 1972) o de la llamada etnometodología (Garfinkel, 1984). A pesar o junto a su formación en Alemania mediante la sociología de Max Weber, William Isaac Thomas plantea varias ideas que dan pie a pensar que la antropología urbana implementada en Chicago entre 1915 y 1935 era pragmatista o había sido pragmatizada no solo por autores claves como John Dewey o George H. Mead, sino por la propia posición teórico-metodológica de sus líderes intelectuales. Conceptos como definición de la situación (Thomas, 2005) o universo del discurso conllevan una connotación pragmatista, siempre que entendamos por situación un campo de actividades definido por la interacción (o transacción, como hubiese dicho Dewey) entre un organismo y su entorno (Garreta, 1999: 3) por un lado, y por universo del discurso, un concepto propio de la lógica de las relaciones donde la interacción verbal forma parte de un orden deíctico, semántico y pragmático implícito cuya actualización muestra al mismo tiempo su potencial y limitación por otro.

Dicho de otra manera, interactuar en una determinada situación social es ejercer una intencionalidad con y contra un entorno social determinado por el juego anterior de las reglas que en él prevalecen. Cuando voy a la tienda a comprar cigarros, existe una intención social mía relacionada con el consumo de tabaco que se implementa en un medio social determinado (el mundo de las tabaquerías) y de acuerdo a ciertas expectativas institucionales y culturales que sirven de reglas iniciales y encuadre preliminar 
para el desarrollo de este tipo de interacción (compra-venta de unos cigarrillos). Si utilizo a propósito los predicados de "iniciales" y "preliminar" para calificar el inicio de la situación es porque aunque ésta tenga una forma típica y rutinaria, una situación como la compra de tabaco es siempre una construcción social, la actualización de una tipificación social. Cada situación, por ende, tiene un orden social (su "tipicalidad") y un orden práctico (su realización) y entre ambos existe una distancia pragmática que consiste en decir que cualquier acto, si bien está orientado socialmente, no está determinado de antemano, lo cual significa que su curso y desenlace no son del todo predecibles. De ahí que una situación puede construir realidades sociales (esto remite al famoso teorema de Thomas acerca de la profecía auto-realizadora) y definir su horizonte normativo, es decir discursivo: aquello que se permite y aquello que se prohíbe.

Ahora bien la llamada crisis de la interpretación sociológica (esto es, el momento de elección entre varias posibilidades de lectura y cuáles serían los criterios para llevar a cabo esta decisión hermenéutica) tiene que ver con la crisis del significado que padecen las grandes instituciones que han enmarcado durante varias décadas la vida social de las sociedades contemporáneas: el trabajo, la familia, la política y sus partidos, la religión e incluso el Estado-nación. Hoy día las organizaciones sociales estriban en actividades productivas o de servicio cuyas fronteras legales son cada vez más borrosas y porosas; en expresiones espirituales no siempre eclesiales donde resalta la religiosidad de los sujetos que las comparten; en relaciones familiares reacomodadas y complejas que obligan a los antropólogos a repensar los lazos de parentesco; en formas alternas de construir la acción y la vida políticas desde abajo y de modo directo y participativo; en nuevas maneras de significar o de refrendar las identidades sociales y culturales. Parece que el mundo se deshace a veces de manera precipitada, pero parece también que se está reconstruyendo. Los procesos sociales son nuevos. Articulan dimensiones locales y globales, individuales y colectivas. La llamada globalización de 
los intercambios de toda índole ha posibilitado el advenimiento de este nuevo mundo. A veces es esquizofrénico cuando lo arcaico cohabita sin tocarse o toparse con lo "sobre moderno" como es el caso de las sociedades urbanas con sus mecanismos de segregación, a veces es híbrido cuando se articulan estrechamente lógicas dispares como es el caso de ciertas formas de producción de empresas transnacionales con alta tecnología en un sitio y condiciones de producción y explotación en otro lado que pertenecen a otros tiempos de dominación. Pero a veces es creativo, cuando la globalización pone en escena a grupos hasta ahora invisibles: grupos étnicos, de mujeres o de orientación sexual diferente.

Este nuevo mundo pone de relieve la necesidad de organizar un debate abierto sobre las nuevas identificaciones y el devenir de las llamadas "identidades primordiales", sexuales, religiosas, nacionales o étnicas, y cuya problemática bien parece girar en torno a las cuestiones de la referencia y de la creencia. En este sentido, el pensamiento pragmatista puede aportar algunos insumos o soluciones medianas para rescatar la reflexión sociológica del atolladero en que parece estar varada. A manera de hipótesis conceptual echaré mano de tres ideas clave del pensamiento pragmatista: acción creadora, creencia y continuidad, es decir proceso. Asimismo empezaré a sacar las consecuencias de la puesta en circulación de dichos conceptos dentro del lenguaje o los lenguajes sociológicos.

\section{Tres pistas pragmatistas para la reflexión sociológica: "Acción creadora", "creencia" y "continuidad"}

Para efectos de comprensión sobre la relación entre pragmatismo y sociología considero oportuno partir del siguiente presupuesto: el uso pragmatista de los conceptos de creencia o acción nos obliga a construir una reflexión dinámica, es decir relacional, donde una idea va de la mano con otra, donde la oposición o la contradicción no son sino perspectivas mas no la descripción de una realidad en sí. Por más opuestos o distintos que parezcan, los 
binomios creencia-duda o acción-pensamiento son finalmente complementarios cuando se es pragmatista. Muchas sociologías de la acción parten del supuesto que sólo la acción humana es directamente observable (Outhwaite, 1998: 146). De ahí se puede entender por qué, para ciertas propuestas epistemológicas en ciencias sociales, esta constatación se transforma en principio rector. Esto es por ejemplo prominente de la etnometodología cuya fenomenología plantea concretizar el análisis formal (esto es la macrosociología positivista y dominante) y responder los puntos ciegos de éste, del tipo cómo es que la práctica social es práctica o cómo es que el actor social actúa, o cómo es que la socialización como esfuerzo institucional socializa.

La duda sin el soporte de la creencia es una quimera, dicen los pragmatistas, ya que no sólo no se puede lógicamente dudar de todo, sino que también la creencia es por decirlo así el combustible de la duda, su guía. Pragmatistas como Peirce o James consideran que el problema de la creencia no es tanto definir lo qué es -lo cual nos puede llevar muy lejos y hasta el pantanoso terreno de la confusión con la verdad, el conocimiento, la certeza, y con la cuestión de los hábitos- sino entender cómo funciona y bajo qué condiciones. La creencia en tanto expresión de una verdad no es el reflejo de la realidad conforme a un cierto tipo de entorno cultural, sino que es una construcción de la misma, su ampliación. La creencia es un conjunto de experiencias y conocimiento que no es sólo reductible al campo de la religión sino que atañe a todos y cada uno de los espacios donde el hombre construye su humanidad culturalmente situada. No sólo los pragmatistas parten del mundo como es sino que confiesan su adhesión a él. A diferencia de la epistemología positivista fundamentada en la perspectiva etic donde el objeto es separado del sujeto pensante investigador, los pragmatistas no desconfían del sentido común que es otra cara de la creencia. En este sentido, la perspectiva emic sería por decirlo así una suerte de subjetivación de las culturas no tanto como interioridad colectiva, material y simbólica -esto es, un mundo en sí- sino como punto de vista 
situado o como ventana abierta al mundo y cuyo marco posibilita al tiempo que limita la representación del mismo.

Por ello James establece una distinción entre religión y religiosidad (James, 1999), es decir entre institución y fe, entre colectividad e individualidad, entre dogma y verdad práctica. Para Peirce la creencia es un proceso que caracteriza formas de actuar y anclar, con más o menos firmeza, lo que de ellas se deriva (Peirce, 1984:142-150) y para James es, primero que nada, una relación de confianza con este mismísimo mundo en que estamos todos (Lapoujade, 1997: 86-87) y luego un conjunto de hábitos. Consecuentemente significa que toda actividad humana genera creencias y toda creencia orienta la acción, en el entendido de que para los pragmatistas el fin de la acción es el sosiego y el descanso merced a los hábitos. Existe un evidente hilo conductor entre creencia, verdad y práctica y si bien esta continuidad caracteriza la vida de Juan Pérez o de Pedro Martínez también es una manera de dar cuenta de la sociología en tanto que actividad. Los sociólogos creemos muchas cosas que nos son útiles. Damos por sentado, por ejemplo, que una ciencia de la sociedad es posible y hasta deseable en el sentido de que responde al interés general y contribuye al bien común, al tiempo que el balance de las aportaciones de esta ciencia para mejoras sociales es muy irregular por no decir errático, no hay pues una relación directa entre el aumento del conocimiento sociológico sobre la realidad social y la solución a problemas sociales concretos. No por ser micro, es decir supuestamente más cerca de la realidad, la sociología no sólo entienda mejor la situación y la condición de los actores sino tenga la capacidad de solucionarlas o mejorarlas.

La etnometodología convertida por ejemplo en etnología del salón de clase (Mehan y Wood, 1975) no ha permitido problematizar mejor que otros enfoques, fundados en la teoría de la dominación, la situación escolar en las sociedades postindustriales y muchos menos aportar soluciones a la desigualdad escolar. No existe, pues, una correlación entre el aumento del conocimien- 
to sociológico de los problemas escolares y la resolución de éstos. La principal objeción a este comentario consiste en recalcar que un problema social no es un problema sociológico y que se trata de dos quehaceres cuya realización respectiva de vez en cuando se entrecruza. La traducción de uno a otro no es directa, sino requiere ajustes y grados de comprensión: aquello que investiga, interroga, busca, encuentra o crea el sociólogo tiene que ver con un problema de conocimiento -tal como colmar un hueco sobre una realidad poco explorada (ej. la migración hoy en día de adolescentes indocumentados para determinar su envergadura, sus motivos y sus recursos y cómo se compagina con otras formas de migrar ya sean legales o ilegales)- o un problema metodológico y conceptual para generar dicho conocimiento (tal como la escala de observación adecuada por un lado, y no confundir el sustantivo - la palabra- con la sustancia, la realidad que alberga detrás de él para evitar construcciones conceptuales equivocadas por otro). Sin embargo la sociología tiene una dimensión social. Sus actividades son realizadas por sujetos de carne y hueso que no nacieron siendo científicos sociales sino que tuvieron que aprender el oficio y lidiar con sus gajes. Alfred Schütz (1899-1959), cuya sociología fue tardíamente influida por el pragmatismo (1987), consideraba que la sociología era una manera de profundizar o continuar con problemas sociales, mediante un protocolo y técnicas científicas. Además, las ciencias sociales solo son posibles si hay condiciones democráticas reunidas (como la libertad para elegir tal o cual tema de estudio) para su libre ejercicio, lo cual significa que el conocimiento producido por ellas, si bien puede cobrar un carácter frío y distante en cuanto la distancia cobrada con respecto a problemas existenciales, inmediatos y sociales, difícilmente puede quedar apartado del devenir de una organización social. El interés por el conocimiento sociológico está para posibilitar la emancipación del sujeto ciudadano en general, lograr su plena autonomía y libertad, habilitar su capacidad crítica y como decía Dewey (2002: 223-226), convertirse en un control social a cargo de la ciudada- 
nía vigilando la marcha del Estado y sus instituciones. El primer reto consiste en comprender en qué mundo vive uno.

En otra tesitura, se considera que la duda es, pues, atributo de las ciencias sociales, al igual que otras disciplinas científicas, al tiempo que la creencia es netamente anclada en las mentes y prácticas sociales y culturales de los sujetos (Karsenti y Quéré, 2004). De hecho la idea de creencia constituye incluso un óbice para actuar (e investigar), ya que es sinónimo de arraigo, de tradiciones y finalmente de anclaje en una realidad estática. La creencia social se traduce en palabras sociológicas en un habitus, es decir una disposición para actuar de una determinada manera y reproducir estándares sociales en materia de gusto, de moral y representaciones sobre el mundo actual funcionando todas como una doxa, una creencia incuestionable por no plantearse nunca.

Esta división no sólo es epistemológica sino que es una ideología que naturaliza un orden social. William James considera que la creencia por confianza se caracteriza, contrario a la creencia por hábitos, por ser una actitud de anticipación, mas no de previsión. Significa que el actor para actuar requiere principalmente de fe para conseguir su cometido y no tanto de un proyecto o un plan de acción nítidamente definido. La fe en el sentido lato de la palabra no vuelve la acción cierta sino posible. No se trata de actuar dentro del mundo, como si fuera una estructura, un conjunto de relaciones organizadas en sistema. Se trata de relacionarse con él con tal de ensancharlo. La duda es siempre sobre algo, la duda acerca de una vertiente de aquello que era considerado cierto y fehaciente; la duda es el trastorno de una clase de hábitos; la duda, dicen los pragmatistas, no nos deja en paz. Nos compele para actuar hasta terminar con ella, es decir hasta construir nuevos hábitos generadores de sosiego y reposo para el sujeto pensante y actuante. La duda es la irrupción del mundo como experiencia fenomenal en una parte más o menos importante de nuestro orden de creencias. Es entonces la creencia trastrocada y convertida en duda que sirve de momento de arranque para la acción. 
No huelga decir que dicho planteamiento pragmatista devela una serie de consecuencias para la reflexión y el remozamiento de la mirada sociológica sobre la realidad social. Señalaremos entre otros:

1) Los grandes conjuntos de creencias institucionalizados producen potencialmente condiciones favorables para la acción social, esto es el caso de las grandes religiones textuales como el cristianismo o el Islam, las tradiciones culturales o las ideologías orientadas hacia el quehacer de partidos políticos o sindicatos. Manejada como hipótesis esta idea plantea considerar una estructura de creencias como un marco flexible para la acción. No es mucho exagerar decir que esta idea reemite directamente a la tesis de Anthony Giddens sobre la relación entre acción y estructura y su complementariedad (Giddens, 1987). Asimismo esta última idea se relaciona, de alguna manera, con la sociología de la experiencia de François Dubet (1994), donde la socialización mediante el juego de grandes instituciones portadoras de normas termina siendo incompleta o dejando punto ciego para la acción organizada y creatividad del actor (que no expresión de sus pulsiones biológicas o psíquicas)

2) Desde la perspectiva del actor la relación entre acción y creencia expresa un estado de conciencia y posibilita por tanto el control que aquel ha de ejercer sobre ésta. Esta idea pragmatista es muy importante ya que contrarresta la concepción del control social como el efecto de una relación invisible que sojuzga a los sujetos a un poder escondido que sólo la perspicacia sociológica permite ver. Sin embargo autores norteamericanos clásicos como Dewey, Lester Ward (18411913) o Edward A. Ross han concebido el control social como un instrumento político de los públicos frente al dominio de las instituciones del Estado y de los grupos hegemónicos de las sociedades capitalistas (Schaffhauser, 2009: 138-139).

3) El examen pragmatista de la relación creencia-duda devela una relación estrecha entre psicología y sociología convir- 
tiendo a la figura de G.H. Mead en principal protagonista de lo que, mal que bien, llamaría yo una heurística disciplinaria. Lo que nos enseña la propuesta meadiana es darse cuenta que muchos problemas que plantea la psicología no son sino problemas sociales y colectivos donde finalmente el alma, como entidad propia y singular, poco opera o tiene que ver. Mead propone, entonces, sociologizar la ciencia de la singularidad que es la psicología (Brassac, 2005), por dos razones: 1) el lenguaje de la psicología al igual que la filosofía o cualquier otra ciencia social y humana es muestra clara de una confusión que el segundo Wittgenstein señala, esto es entre el sustantivo y la sustancia, además de que sigue considerando la posibilidad de la existencia de un lenguaje privado como es el caso de ciertas patologías como el autismo no genético o la esquizofrenia, y 2) el empirismo radical de William James (Lapoujade, 1997), que considera que primero está la experiencia directa (que no siempre inmediata) de algo y luego de ella se desprende la dicotomía entre sujeto y objeto, es otra tanta crítica asestada al pensamiento de la tradición psicológica.

4) La relación creencia-acción mediada por el par paradójico de la duda y la confianza permite entender la tesis de la acción creadora que encontramos tanto en Peirce y James como en Dewey y Mead, esto es, la idea de que la acción humana, lejos de ser sólo el fruto de un cálculo o la expresión de un imperativo categórico, es también expresión de una creación situada en el entendido que por creación se trata de la producción de nuevas expectativas para actuar y trasformar el mundo, de la producción de nuevas conductas o nuevos valores que principian el establecimiento de una nueva normatividad. Dicha creación, además, tiene que ver con una estetización del mundo y de la vida social que sale del campo de las Bellas Artes y evade el control de los custodios de la legitimidad artística. La acción creadora no es más que la humanidad plasmada en el pasmo de la acción. 
La sociología como ciencia, cuyos objetos centrales han sido sucesivamente y/o simultáneamente la sociedad, la acción social, la imitación social como creía el más pragmatista de los primeros sociólogos, Gabriel de Tarde (Lapoujade, 1997: 116), las interacciones simbólicas o los resultados alcanzados por los hombres (Ward, 1906), se está enfrentando hoy día al problema de la re-definición de su papel en la esfera pública. Espacio de crítica al servicio de la inteligencia social o agente de regulación de los conflictos sociales, tal parece ser el dilema la sociología. La crítica postmoderna hacia la tradición positivista de las ciencias sociales que llegaron a ser cómplices pasivas y hasta activas del desastroso (i.e. guerras mundiales del siglo $\mathrm{XX}$ ) e inconcluso proyecto ideológico de la modernidad capitalista, no ha permitido, pese a la contundencia de su crítica que terminó por desencantar el propósito de las ciencias sociales, proveer la reflexión sociológica de un nuevo horizonte hacia el cual pudiera dirigir los pasos de su investigación. Tempranamente el pragmatismo, en tiempos de la llamada ecología urbana de William I. Thomas, Robert E. Park, ha buscado orientar la antropología urbana hacia la atención de problemas sociales concretos surgidos del desarrollo desenfrenado de la ciudad de Chicago y del flujo constante de comunidades migrantes procedentes prácticamente de todas las culturas del planeta. Esto es el caso de Hull House, un espacio de atención para grupos vulnerables, y de Jane Addams, discípula intelectual de John Dewey y George H. Mead. Este periodo corresponde también a la emergencia de las nuevas ciencias sociales en Estados Unidos, más empiristas, más pragmatistas, menos hegelianas. Figuras como el economista Thorstein Veblen, el jurista Oliver W. Holmes o el historiador James H. Robinson y los ya mencionados sociólogos de la llamada escuela de Chicago despuntaron (Garreta, 1996).

En aquellos tiempos la sociología aplicada al ámbito urbano, el protestantismo, la democracia, el feminismo y el pragmatismo constituían un eje de reflexión y acción. Se trataba de reformar la sociedad norteamericana empezando por el caso de Chicago 
con tal de mejorar lo que tenía que serlo y salvaguardar aquello que era "útil" para los desprotegidos y los marginados (Miranda Aranda, 2003). Para ello la duda era necesaria pero también la creencia y la fe en la sociedad norteamericana como espacio liberal en el sentido que dicha ideología cobraba para las postrimerías del siglo XIX e inicios del siguiente. El conocimiento, según Dewey, no era sino un instrumento puesto al servicio de la experiencia. Recordemos ahí la idea de proyecto que tantas consecuencias tuvo en la reforma y remozamiento de proyectos educativos tanto en EE.UU. como en México (Schaffhauser, 2010 y 2012).

Es importante también entender que Park, quien fuera líder de la ecología urbana, había sido periodista de investigación trabajando muy de cerca la condición de la comunidad negra en el sur del país, antes de incorporarse a la Universidad Harper de Chicago cuando William I. Thomas lo mandó llamar. Significa que la relación entre pragmatismo y sociología urbana fue innovadora en el sentido de que valores como acción, fe, conocimiento, duda, creencia, democracia terminaron cuajándose en un mismo proyecto científico, sin embargo, totalmente carente de referencias al marxismo y claramente ajeno a la tesis de la revolución como herramienta del cambio social. La escuela de Chicago nunca ha sido pragmatista sino inspirada por el pragmatismo. Puso en práctica lo que Dewey o Mead planteaban. Su pragmatismo descansó en la novedad, la conjunción de talentos, la interdisciplinariedad, agrupados todos en torno a la resolución de un problema: cómo hacer que la migración no sea solo factor de desorganización social. He ahí también otra fuente de explicación sobre la importancia del concepto de continuidad que hacer fluir el conocimiento de un campo disciplinario a otro.

\section{Consideraciones finales}

A 54 años de publicarse el curso sobre pragmatismo dictado por Emilio Durkheim en la Sorbona, y en cuyas sesiones presenta y 
crítica principalmente la teoría pragmatista de la verdad de William James, C. Wright Mills en su libro sociología y pragmatismo construye una sociología del pragmatismo empezando por el estudio del perfil social, cultural y político de sus principales figuras y terminando por interrogarse sobre la oportunidad del papel del pensamiento pragmatista en el periodo del New Deal del presidente Roosevelt. El autor de Los cuellos blancos nunca desmintió su parentesco intelectual con la filosofía pragmatista, lo cual es un dato interesante a la hora de volver a leer la obra de Mills. El pragmatismo ofrece a la sociología el horizonte que el poder de su crítica amerita, esto es, la posibilidad de sumarse a la acción social general en una realidad realizable. Bajo esta perspectiva, la "experiencia sociológica" que permite reconstruir con ensayos y errores su propósito de conocimiento e incidencia en las transformaciones sociales y redefinir así su programa de investigación seria, a la postre, otra manera de designar dicha disciplina donde su contenido teórico se case con su aplicación a casos concretos. Con el pragmatismo los sociólogos re-descubrimos que nuestra ciencia es un proyecto y no sólo una actividad institucionalizada supeditada económicamente a la lectura política liberal de la realidad social por grupos hegemónicos. El desafío consiste en que la sociología siga formando parte de lo que el sociólogo Charles Cooley (1864-1829) llamaba "la inteligencia social" y que, en palabras de G. H. Mead, su proyecto sea prueba de una "acción creadora situada", esto es, una experiencia puesta al servicio de la condición y conducta ciudadanas y del progreso de los valores democráticos (Dewey, 1949 y 2004 y Cefaï y Joseph, 2002). En este sentido el interés del pragmatismo para la sociología es, en palabras de Jürgen Habermas (1973), emancipador y en tanto que fuente de conocimiento ofrece una alternativa para evitar el enclaustramiento de esta disciplina de las ciencias sociales en su tecnificación y burocratización. En esta veta encontramos hoy en día sociólogos como Richard Sennett o Randall Collins que si bien difieren en cuanto a temas de estudio (uno versa sobre el trabajo en tanto que el otro sobre las emociones y su tra- 
ducción en actos violentos) comparten ambos y otros como Luc Boltanski una misma postura que consiste en una pragmatización paulatina de la sociología que tiene que ver con comprender mejor la diversidad social en que estamos ubicados todos hoy en día, en renunciar a todos los esencialismos y en restablecer una confianza con el futuro. Para ello el pragmatismo como bien lo había notado Alfred Schütz, cuya sociología tiene la virtud de combinar armónicamente a Husserl con Max Weber y el pragmatismo, la sociología tiene todavía por delante un reto mayor que es el problema del estatuto del sentido común en la investigación tanto aquella contra la cual lucha el sociólogo a través del manejo de sus propios prejuicios de clase para propiciar la siempre hipotética ruptura epistemológica, como para atender y respetar cabalmente la opinión del agente o actor que se convierte en su informante. La sociología es tradicionalmente una ciencia de la relación: estudia (el misterio de) sus modalidades sociales y culturales y reflexiona sobre cómo fortalecer los vínculos entre los hombres de acuerdo a valores emancipatorios. Si bien el pragmatismo no es una doctrina filosófica sino una metodología para aclarar nuestras ideas y la relación entre las esferas de lo práctico y de la teoría, puede ser una gran ayuda para lograr este cometido sociológico y consolidar sus frutos.

\section{Bibliografía}

Austin, John Langshaw, 1955, Cómo hacer cosas con palabras, Edición electrónica, www.philosophia.cl / Escuela de Filosofía Universidad ARCIS.

Boutroux, Émile, 2003 (1911), William James. París: Vigdor.

Brassac, Christian, 2005, “La réflexion de George Mead en psychologie sociale francophone: réflexions sur un paradoxe". En Les Cahiers Internationaux de Psychologie Sociale, 66, xx-xx.

Cefaï, Daniel et Joseph, Isaac, coordinateurs, 2002,. Héritage du pragmatisme. Conflit d'urbanité et épreuves du civisme. París: Editions de l'Aube, coll. Société et Territoire. 
Collins, Randall, 1996, Cuatro tradiciones sociológicas. México: UAMIztapalapa.

Deledalle, Gérard, 1999, Sur la philosophie américaine. Louvain: De Boeck, coll. Le point philosophique.

Dewey, John, 1993, Logique. La théorie de l'enquête. París: Presses Universitaires de France.

Dewey, John, 2004, Democracia y educación. Madrid: Ediciones Morata, 2004.

Dewey, John, 2000, La miseria de la epistemología. Ensayos de pragmatismo. Madrid: Biblioteca Nueva.

Dewey, John, 1949, El arte como experiencia. México: Fondo de Cultura Económica.

Dubet, François, 1994, Sociologie de l'expérience. París: Seuil.

Durkheim, Émile, 1999, Le suicide, París: PUF, coll. Quadriges.

Durkheim, Émile, 1981, Pragmatisme et sociologie. Cours inédit prononcé à la Sorbonne en 1913-1914 et restitué par Armand Cuvillier d'après des notes d'étudiants, París: Vrin.

Garfinkel, Harold, 1984, Studies in ethnomethodology. Cambridge: Polity Press.

Garreta, Guillaume, 1999, «Situation et objectivité. Activités et émergence des objets dans le pragmatisme de Dewey et Mead» en Fornel, M. \& Louis Quéré (ed.). La logique des situations, París: Raisons Pratiques nú 10, Éditions de l’EHESS.

Garreta, Guillaume, 1996, «Le pragmatisme et les sciences sociales aux Etats-Unis (1880-1920)». París: Université de Paris I, Panthéon Sorbonne, UFR e Philosophie.

Geertz, Clifford, 1999, Los usos de la diversidad. Barcelona: Paidós: ICE de la Universidad Autónoma de Barcelona.

Giddens, Anthony, 1987, La constitution de la société. París, Presses Universitaires de France.

Goffman, Erving, 1963, Estigma, la identidad deteriorada, Buenos Aires: Amorrortu, 1963.

Goffman, Erving, 1972, Internados. Ensayo sobre la situación social de los enfermos mentales. Buenos Aires: Amorrortu.

Habermas, Jürgen, 1973 (1968), La science et la technique comme «idéologie». París: Gallimard. 
James, William, 2004, La voluntad de creer. Madrid: Ediciones Encuentro.

James, William, 1980, El significado de la verdad. Buenos Aires: Aguilar.

James, William, 1999, Las variedades de la experiencia religiosa: estudio de la naturaleza humana. Barcelona: Península.

James, William, 1975, Pragmatismo. Buenos Aires: Aguilar, Biblioteca de iniciación filosófica.

Joas, Hans, 2007, George Herbert Mead. Une réévaluation contemporaine de sa pensée, París: Economica, coll. Études Sociologiques.

Joas, Hans, 2002, Creatividad, acción y valores: hacia una teoría sociológica de la contingencia. México: UAM-Iztapalapa.

Joas, Hans, 1999, La créativité de l'agir. Préface d'Alain Touraine. París; Cerf.

Joas, Hans, 1997, El pragmatismo y la teoría de la sociedad. Madrid: Universidad de Castilla y de la Mancha.

Karsenti, Bruno et Quéré, Louis, éditeurs, 2004, La croyance et l'enquête. Aux sources du pragmatisme. París: Editions de l'Ecole des Hautes Etudes en Sciences Sociales, 2004.

Kuhn, Thomas Samuel, 1971, La estructura de las revoluciones científicas. México: Fondo de Cultura Económica.

Lapoujade, David, 1997, William James. Empirisme et pragmatisme. París: Presses Universitaires de France, 1997.

Mead, George Herbert, 1990, Espíritu, persona y sociedad. Desde el punto de vista del conductismo social. Introducción de Charles W. Morris, México: Paidós, studio básica, 1990.

Mehan, Hugh and Wood, Houston, 1975, The reality of ethnomethodology. San Diego: Wiley.

Mills, Charles Wright, 1968, Sociología y pragmatismo. Introducción de Irving Louis Horowitz. Buenos Aires: Siglo Veinte.

Miranda Aranda, Miguel, 2003, "Pragmatismo, interaccionismo simbólico y trabajo social. De cómo la caridad y la filantropía se hicieron científicas". Tesis Doctoral en antropología social y cultural, Tarragona: Universidad de Tarragona, 2003.

Outhwaite, William, 1998, «L'actualité du paradigme herméneutique». pp. 135-148, en Intellecta, 1-2, 26-27, 1998. 
Peirce, Charles S., 1984, Textes anticartésiens. Présentation et traduction de Joseph Chenu. París: Aubier, coll. Philosophie de 1'Esprit.

Peirce, Charles Sanders, 1978, Ecrits sur le signe, textes rassemblés, traduits et présentés par Gérard Deledalle. París: Seuil.

Peirce, Charles Sanders, 1978, Lecciones sobre el pragmatismo. Buenos Aires: Aguilar.

Peirce, Charles S., 1877, "Fixation of belief", en Popular Science Monthly, November.

Peirce, Charles S., 1878, "How to make our ideas clear?", en Popular Science Monthly, January.

Putnam, Hilary, 1999, El pragmatismo. Un debate abierto. Barcelona: Gedisa, col. Filosofía.

Ryle, Gilbert, 2005, El concepto de lo mental. Barcelona: Paidós, 2005.

Schaffhauser, Philippe, 2012, "El pragmatismo indigenista de Moisés Sáenz o ¿cómo encontrar ideas de John Dewey en Carapan, bosquejo de una experiencia?", pp. 177-208, en Marco Antonio Calderón Mólgora, Educación indígena, ciudadanía y Estado en México siglo XX, Zamora: El Colegio de Michoacán.

Schaffhauser, Philippe, 2010, «Indigénisme et pragmatisme au Mexique: L'expérience éducative de Moisés Sáenz Garza», Journal de la Société des Américanistes, 2010, 96-1.

Schaffhauser, Philippe, 2004, «Note sur quelques aspects du pragmatisme». www.univ-perp.fr/lsh/socio.

Schütz, Alfred, 1987, Le chercheur et le quotidien. Phénoménologie des sciences sociales (traduction d'articles sélectionnés à partir des Collected Papers), traduction par Anne Noschis-Gillieron, París: Méridiens Klincksieck.

Thomas, William, Isaac, 2005, “La definición de la situación”, 6 pág. Trad. de Eva Aladro, Cuadernos de Información y Comunicación, número 10.

Ward, Lester, 1906, Sociologie pure. París: V. Giard et Brière, 1906.

Wittgenstein, Ludwig, 1975, Tractatus lógico philosophicus. Madrid: Alianza, 1975.

Wittgenstein, Ludwig, 1988, Sobre la certeza. Barcelona: Gedisa. 